\title{
Encouraging SME eCollaboration - The Role of the Champion Facilitator
}

\author{
Michael Jones and Lois Burgess \\ University of Wollongong, NSW, Australia
}

mjones@uow.edu.au; lburgess@uow.edu.au

\begin{abstract}
Technology has done many things for small businesses. In one sense small business has been harmed through the advance of technology, which, from a competitive perspective, has made the world a much smaller place. To balance this, technology now provides the means for small businesses to collaborate and build complementary skills to provide a better competitive standing in the world market. Electronically enhanced collaboration, or eCollaboration, allows firms to transcend the boundaries of space and time, permitting asynchronous communication and other Information Communication Technology (ICT) enablers. eCollaboration provides participants clear market advantages, not least among these is profit. Gains can also be realized in areas like knowledge management, increased customer service, optimized supply chains, and better inventory control.

Participants from 70 Small businesses in Southern Sydney were interviewed, observed, and participated in focus groups. Data were collected and analyzed using NVivo and Grounded Theory; from this data an integrated model is developed which provides guidelines for optimum facilitation and management of eCollaboration. Two critical needs were developed - these were hard and soft needs; two value-add needs were found - these are marketing and feedback. By satisfying these needs eCollaboration Champions - people or institutions who can facilitate, support, and guide collaborative relationships - can better ensure eCollaboration success.
\end{abstract}

Keywords: eCollaboration, Collaboration, SMEs, NVivo, Grounded Theory, ICT, Facilitation, Mentoring.

\section{Introduction}

There is a great amount of discussion in the literature about the importance of firms, especially small to medium enterprises (SMEs), to work together and maneuver from a position of competitiveness to one of collaboration (Cheng, Love, Standing, \& Gharavi, 2006; Ginige, 2006; Lawson, Hol, \& Hall, 2007). Popular strategies exist to leverage synergies, expand economies of scale, increase market access and size, and optimize supply chain advantages (Jones \& Burgess

Material published as part of this publication, either on-line or in print, is copyrighted by the Informing Science Institute. Permission to make digital or paper copy of part or all of these works for personal or classroom use is granted without fee provided that the copies are not made or distributed for profit or commercial advantage AND that copies 1) bear this notice in full and 2) give the full citation on the first page. It is permissible to abstract these works so long as credit is given. To copy in all other cases or to republish or to post on a server or to redistribute to lists requires specific permission and payment of a fee. Contact 0HPublisher@InformingScience.org to request redistribution permission. 2009b). With the enhancement of eCollaboration, firms can also learn to integrate systems, enhance knowledge transfer and retention, and increase redundancy of labor and capital (Lawson et al., 2007). The electronic enhancement of collaboration, through eCollaboration, also permits firms to transcend the boundaries of space and time, allowing asynchronous communication and other Information Communication Technol- 
ogy (ICT) enablers (Burgess \& Sargent 2007).

The problem, however, is that a majority of SMEs fail in their attempts to realize these advantages through eCollaboration for one very strong and clear reason - there is little or poor utilization of a facilitator or project champion (Ginige, 2006). Based on the analysis of a series of focus groups in three industry sectors in Sydney, Australia, this paper takes a look at this problem. The paper will present empirically grounded discussion on how firms can better adopt the services of a facilitator - a champion, either internal or external - and what such a person, or people, can do to better ensure eCollaboration success.

\section{What is eCollaboration?}

Collaboration is the process by which two or more businesses work together to achieve a common purpose or goal using shared resources and co-commitment. eCollaboration is a new approach to the formation and maintenance of cooperative enterprise involving the introduction of electronic communication tools to facilitate collaboration. With eCollaboration the interface between firms changes and can take a multitude of forms. Most common are the Internet and email. However, businesses can embrace a range of tools from as simple as a mobile phone or SMS (text) through to complex systems like SharePoint, web sphere, and other management information systems. eCollaboration can be understood as "the computer mediated process of two or more (dislocated) people working together on a common purpose or goal, where the participants are committed and inter-dependent and work in a common context using shared resources, supported by (web-based) electronic tools" (Mayrhofer \& Back, 2003, p. 7). Through eCollaboration, stakeholders are able to network between the fields of computer-human interaction, computer-supported cooperative work, and electronic commerce.

eCollaboration provides participants clear market advantages. A commonality of information exchange enables an expedient path of communication that establishes a sense of exclusivity to only those members with collaborative access (Ma, 2009). Seamless knowledge management and storage is also achieved (Meixner \& Haas, 2008). Transaction costs can be reduced, and a larger population of stakeholders can be included in transactions for minimal marginal expense (Meixner \& Haas, 2008). Firms are able to engage in value creation through enhanced inter-partner learning and by "combining internal and external resources in innovative ways" (Ma, 2009, p. 68). Shared information systems also enable firms to optimize supply chains, reduce inventory costs and risks, improve customer service, and better manage forecasting and planning (Ma, 2009). Some of the problems related to intercultural conflict that are common with conventional forms of collaboration may be avoided through a greater reliance on the virtual environment associated with eCollaboration (Stern \& Hicks, 2000).

In some situations, eCollaboration may have detrimental effects. Firms will differ in their levels of technological acceptance. These differences can lead to inequities, where the more technologically capable firm could take advantage of their weaker counterparts (Jones \& Burgess, 2009a; Ma, 2009). The virtual advantages of eCollaboration may also become a substitute for a physical presence. Firms must maintain physical contact to produce functional relationships; not least among these is the need to build a sense of trust with your collaborators (Jones \& Burgess 2009a). eCollaboration is also at the mercy of the technological 'weakest link'. As a result, collaborating teams are perceived as being only as good as the worst information management and communication system amongst the partners. For example, the quality of a partner's poor internet site may reflect across the whole group of collaborators (Ma, 2009).

eCollaboration has the potential to contribute to business success. However, it is a function of business that does not come easily or naturally in most cases, and it has the possibility of going wrong in some cases. To have a better chance of success collaborators need a person or body to 
assist with the facilitation of their collaboration. In the first instance this can be an organization which assists with networking. Following this, collaborators will benefit from having a champion. A champion in this case is someone who is either involved in the partnership, or who is external to it, but who may be able to support and guide the relationship to foster the advantages, and steer around the disadvantages (Ginige 2006; Jones \& Burgess 2009b).

This paper reports the results of a study of a number of SMEs, located in Sydney's southern suburbs, which are operating at various levels of eCollaboration experience, ranging from those who have not delved into collaborative business relationships through to those who have a number of successful collaborations under their belt. The aim of the paper is to discover and understand the mechanisms that enable or inhibit successful facilitation of eCollaboration. To put it simply: if eCollaboration is such a good thing, and if it is best when it is facilitated by a champion, what does this champion need to do to ensure success?

\section{Method}

A qualitative approach was used for data collection in this study. Three methods were employed throughout the research process: focus groups, semi-structured interviews, and observations.

\section{Focus Groups}

Focus groups were conducted with representatives from three different industry clusters: a defense supply network, an information technology (IT) cluster, and a marine association. In total, the focus groups involved more than 70 participants. Each encounter was facilitated by an experienced moderator and a scribe. The size of each group was kept between eight and ten participants to encourage equal participation (Krueger, 1998). Group consensus was not sought during the session; instead each participant was encouraged to provide their opinions and experiences (Morgan, 1997). The goal of each focus group was to allow candid discussion around a range of preorganized topics. These topics were presented in the form of structured questions. See Figure 1.

\section{Semi-Structured Interviews}

Multiple interviews were conducted in person, ranging from brief informal discussions averaging around five-minutes in duration at cluster events to planned 30 minute in-depth interviews. These interviews followed a semi-structured interview protocol that allowed probing on issues central to the interviewee's experience and background in eCollaboration. Semi-structured interviews can provide the researcher with a deeper understanding of the phenomenon under study (Rowan \& Huston, 1997).

\section{Observations}

Notes were taken at two regional cluster meetings. This research method focused on the interaction between cluster members and how that dynamic contributed to or inhibited successful collaboration during the session. Opportunities were also sought to speak with businesses, cluster facilitators, and others involved in collaboration and to observe clusters and collaborative projects in action. Parties were generally very willing to cooperate and assist the research in any way they could. 

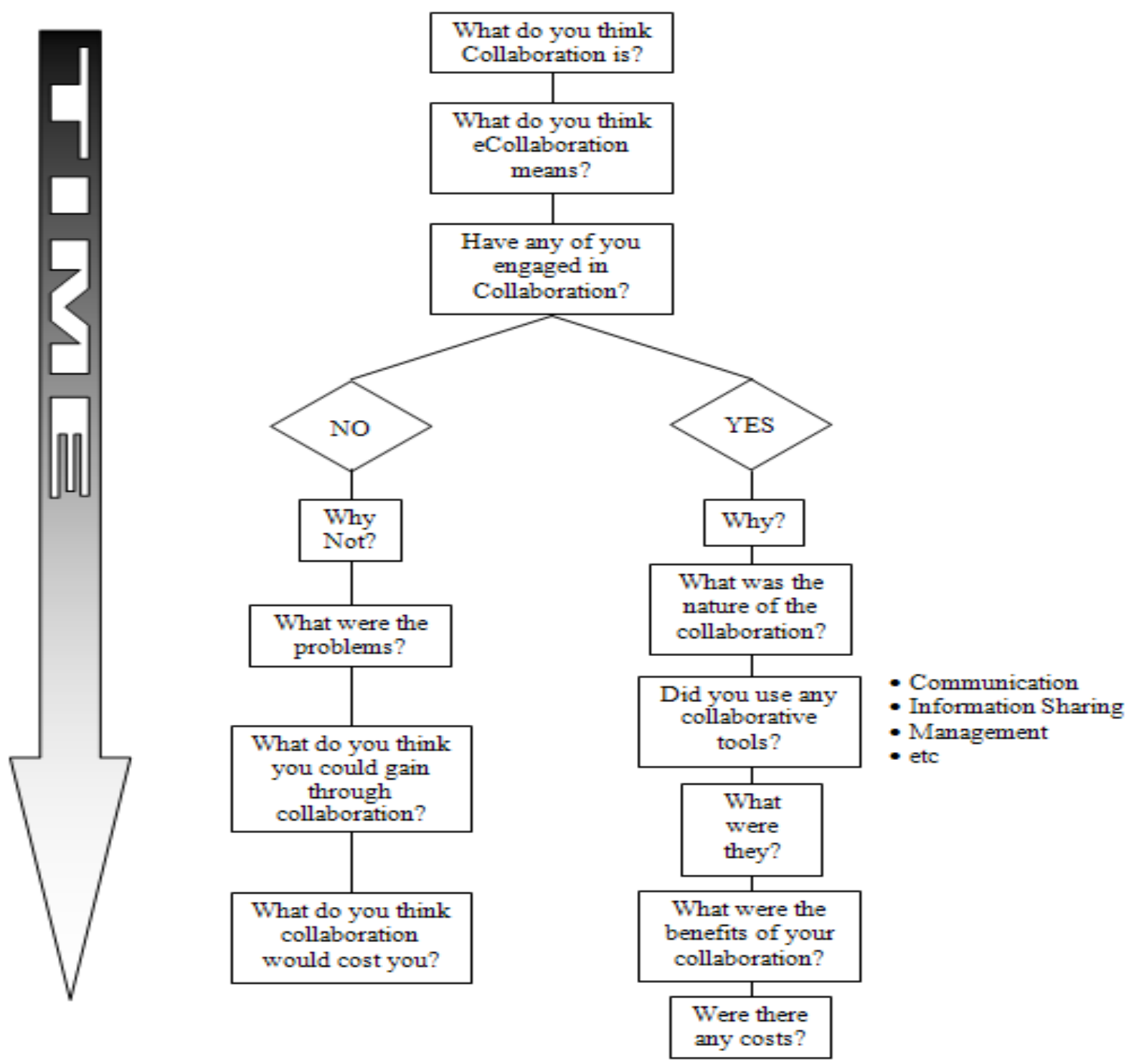

Figure 1. Focus Group Questions

\section{Recruitment}

The method of recruiting participants for the study was based on purposive sampling taking an opportunistic focus (Patton, 1990). This allowed for flexibility in directing the research to interesting topics that arose during the process. Individuals and groups with some experience in collaborative projects were engaged to elicit their voluntary participation in the research in an endeavor to uncover greater depth on an appropriate topic.

\section{Analysis}

Data were collected and compared following the principles of grounded theory. Grounded theory "is an inductive, theory discovery methodology that allows the researcher to develop a theoretical account of the general features of a topic while simultaneously grounding the account in empirical observations or data" (Martin \& Turner, 1986, p. 141). Grounded theory provides a detailed, 
rigorous and systematic method of analysis, which has the advantage of reserving the need for the researcher to conceive preliminary hypotheses, thus providing greater freedom to explore the research area and allow issues to emerge (Bryant, 2002; Glaser, 1978, 1992, 1998, 2001). As a consequence, grounded theory is useful in providing rigorous insight into areas which are relatively unknown to the researcher.

The process of grounded theory utilizes three stages: open coding, selective coding, and theoretical coding (see Figure 2). Analysis begins with open coding, which employs constant comparison and memoing, and results in themes, sub-categories, and core categories. As categories and gain depth, constant comparison compels the researcher to begin to reflect on the data and to conceptualize.

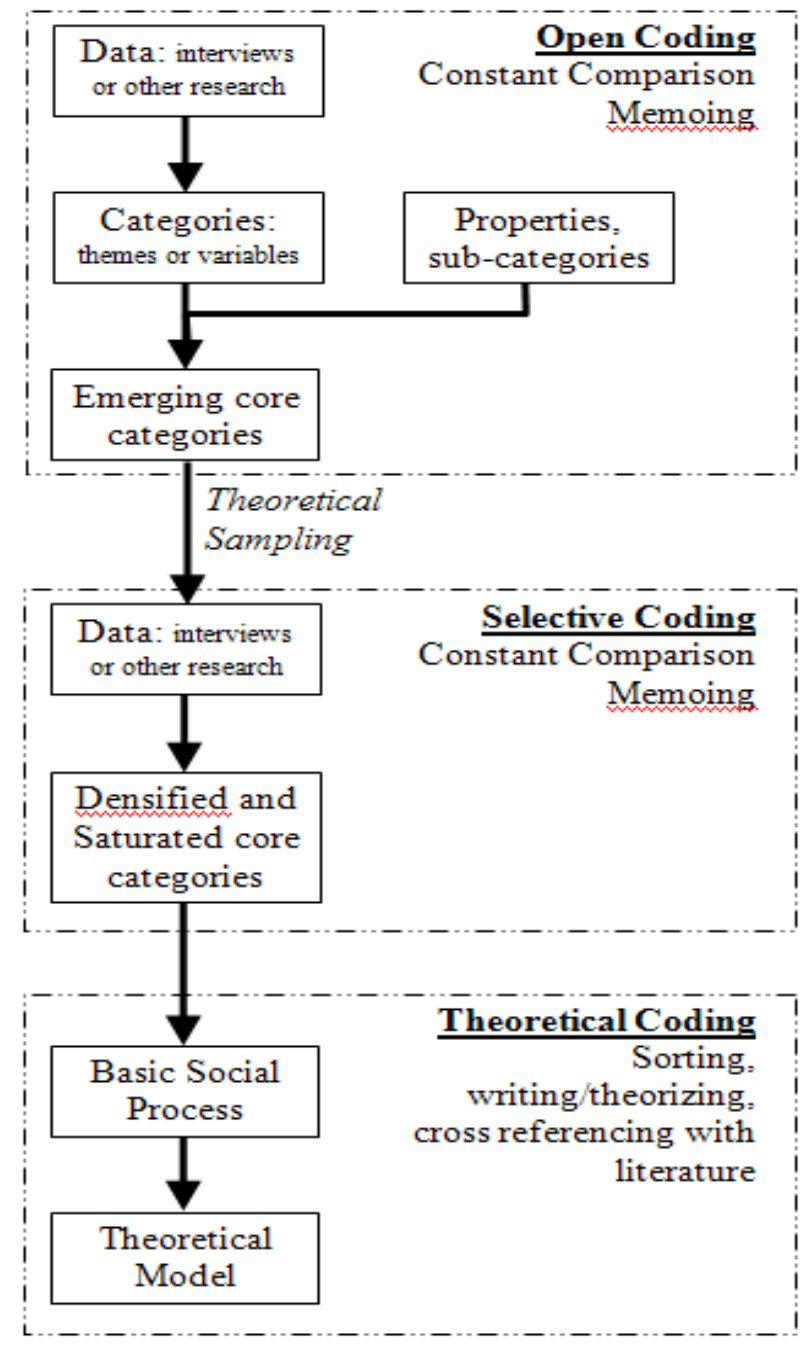

Figure 2. The Process of Grounded Theory

The second stage of coding - selective coding - also employs constant comparison and memoing. This stage results in dense, saturated core categories. Through theoretical coding, the third stage, the core categories are sorted, written, theorized, and cross-referenced with literature. The result of this last stage of coding is a basic social process and a theoretical model. This is the final product of grounded theory research.

Data were analyzed using NVivo. The object of NVivo analysis is to deconstruct blocks of data through fragmentation and then have them coalesce into collections of categories which relate 
conceptually and theoretically and which make assumptions about the phenomenon being studied (Jones, 2005). This is a process of "decontextualizing and recontextualizing" (Richards, 2002, p. 200). The emerging sets of data are thematically abstract and provide objective insights and meaning relevant to the research question.

The qualitative method adopted here provides rich insight and in-depth information on the topic. However, the nature of the exploratory qualitative research presupposes that results cannot be generalized for a population (Hanson, 2008; Onwuegbuzie \& Leech, 2007). Reductive assumptions would have to be made to do this that would sacrifice validity of the data. Furthermore, the opportunistic approach to recruiting participants means that no specific or representative sample is taken. This suggests that results can only be compared using subjective judgments of the context in which respondents provided answers.

The value of the diverse, in-depth information collected by these methods on an exploratory basis, justifies these methodological limitations.

\section{Who or What is a Champion?}

Throughout this paper we use the term 'champion', and in so doing we incorporate several assumptions about the term. In this section we intend to clarify what we mean when the term champion is used.

A champion can be an individual or a group of individuals. However, when the term is used here we mean that, in the majority of cases, a champion will be a network entity that is led by one or more people. This network will have members. These members are the current, or potential, collaborators. The network of members may be led by a representative committee or by independent individuals. The champion may be voluntary and unpaid, or delegated and paid, or any combination of these two factors. They may also be a government body or association. For example, the $\mathrm{I}^{\mathrm{n}}$ SITE conference is a champion. The champion comprises a number of individuals, who are not remunerated, and who are a representative committee. While $\mathrm{I}^{\mathrm{n}}$ SITE doesn't go as far as proactively establishing collaborative projects, it certainly supports collaborations and provides an environment which is intended to germinate future collaboration.

\section{Findings}

As discussed above, data collected from a number of interviews and focus groups are analyzed. The findings of analysis are summarized into a model of the role of an eCollaboration champion in Figure 3, below.

In order to encourage eCollaboration amongst firms there are three major needs the champion, or an organization acting as champion, must satisfy. The first two of these are seen as soft needs and hard needs, respectively. These two needs are 1) Social Integration - soft, and 2) Project Management - hard. These two needs comprise must-do functions that the champion must fulfill. The next need - Marketing - provides the champion a value-add function and works to both justify and sustain its role as champion. The fourth need - feedback - is also a value-add function that can be provided by the champion, however, this role is not seen as being a mandatory need that must be satisfied. Instead, it is something that if done, is appreciated by collaborators. These needs are discussed in greater detail below. 


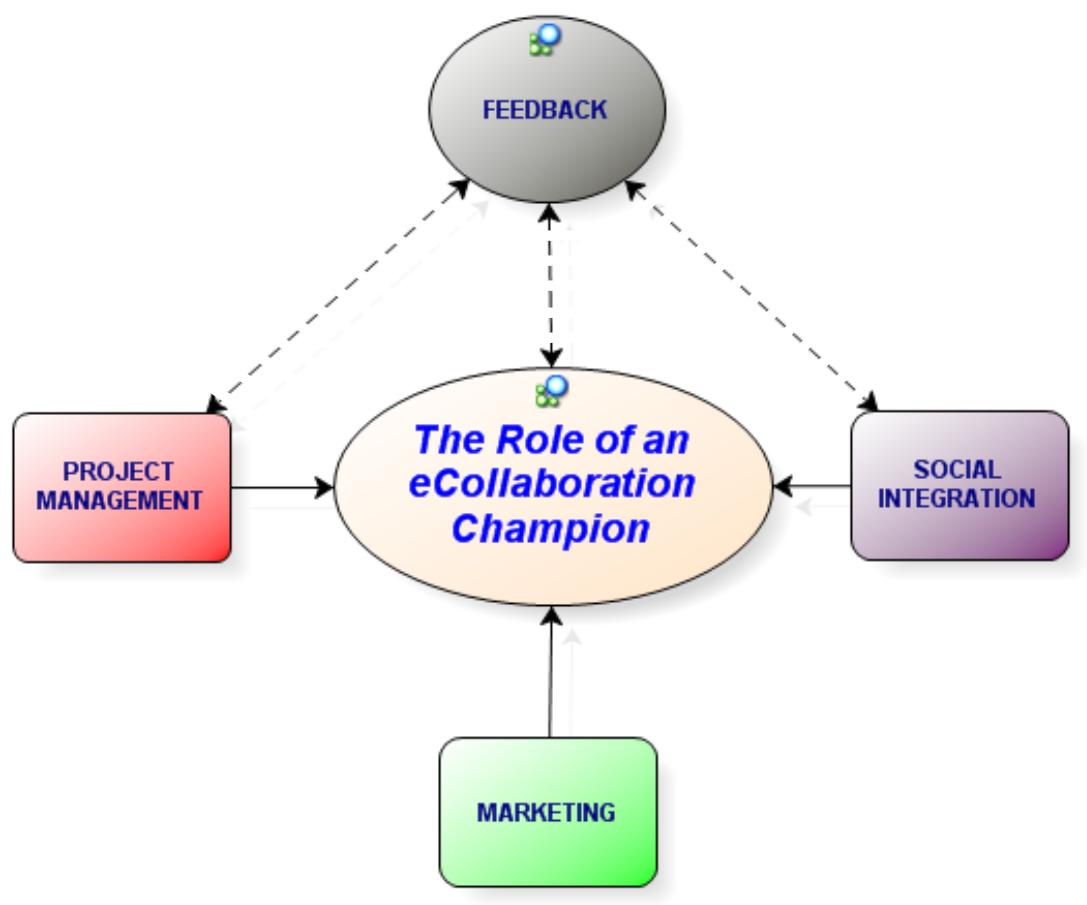

Figure 3. The Role of an eCollaboration Champion

\section{Social Integration}

Social integration is the capacity of the champion to provide for the soft needs of firms wishing to engage in collaboration. Social integration comprises three main functions. The main function of these three is the ability of the champion to facilitate social connection. The next function is to facilitate trust. The third function is to provide mentoring. This third function is especially relevant when firms engage in eCollaboration because of the need to support the technical skills of collaborators. Social integration is illustrated in greater detail in Figure 4, and each function is discussed below.

\section{Create connections}

Through physical and virtual means, champions provide social connection. The first of these, which is more fundamental (and definitely more traditional) works by providing a series of gatherings with common and reoccurring themes, for instance regular speakers who address issues of common interest (e.g., strategies for dealing with the Global Financial Crisis or software to improve production lead time). Associated with this, the champion will provide a venue and refreshments. Usually, a significant amount of time is allocated for members to network. The ability to meet and network seems to have increased value during the lean economic times:

The primary interest in members attending the ... forum meetings is the potential opportunities that may arise from meeting people face to face, and being provided the opportunity to promote individual businesses. As Australia continues to be influenced by the global economic downturn, the opportunity to network and possibilities to create business opportunities has become more attractive to members. (Interview Participant) 


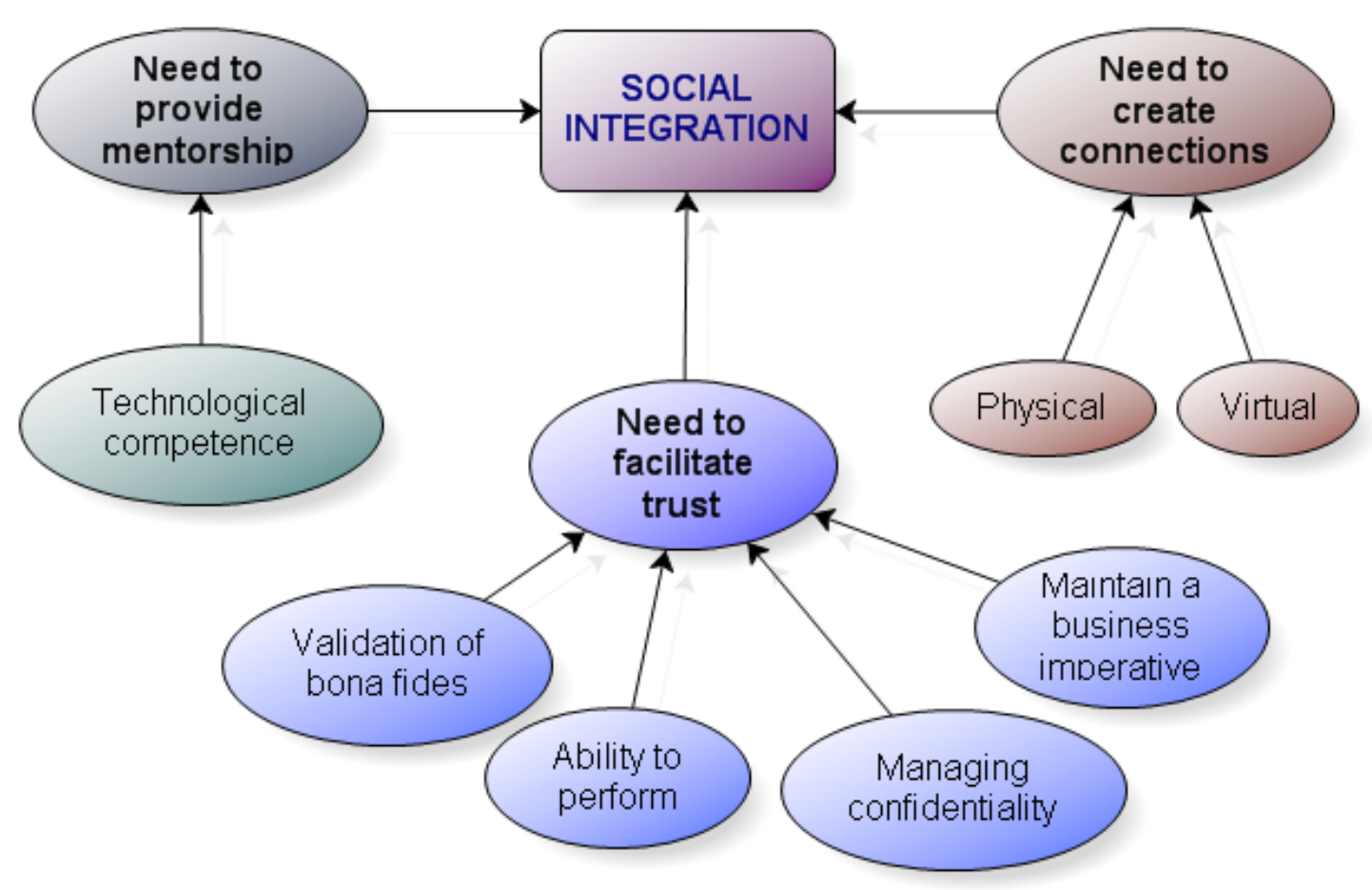

Figure 4. The Role of an eCollaboration Champion as a Social Integrator

A second means of providing this social connection is through a website or web-portal. Of those groups who act as champions, those with web facilities tend to be far more successful:

In a network such as this, suppliers are encouraged by access to a large number of potential buyers and buyers are attracted by a comprehensive choice of suppliers. This cycle acts as an enabler for both suppliers and buyers to be able to network which also encourages collaboration between supplier members. (Focus Group Participant)

In summary, a balance is needed, and it is up to the champion to ensure there is balance. Organizations need access to both face-to-face opportunities for networking, as well as access to electronic systems which support networking. The champion should also encourage members to utilize both sources:

Businesses can manage their involvement independently and organize collaborative projects online at convenience to them. Finally, in the organization of collaboration there must always be a human element. Technology is a tool for making collaboration easier, but there is always a requirement for personal connection to drive the network. (Interview Participant)

\section{Need to facilitate trust}

Trust is seen by many as the major issue in establishing collaboration. It is therefore of primary concern to champions to ensure that trust issues are managed well. Trust can be managed by champions in four steps: First, they must establish bona fides. Second they need to audit collaborators to ensure they are able to perform. Third, the champion should work to manage confidentiality. Finally, the champion should ensure a business imperative is maintained.

Establishing bona fides is an important contribution that a champion can make, because it is difficult for individual firms to perform this function, and they are usually embroiled in the relation- 
ship when a bona fide check should be made. The champion, acting as a third party who is not invested in the outcome of the relationship, can be impartial in ensuring the transparency of each partner. This step is needed because firms who make a mistake in collaborating with the wrong partner will be reluctant to try again - their propensity for trust will have been dampened.

Through assurance of bona fides, the champion can underwrite the collaboration with a necessary level of confidence to enable the collaboration to begin, and begin again next time.

A need to ensure partners are able to perform comes from the phenomenon of small businesses tending to promise they can do more than they actually can. This tendency to push themselves beyond core capabilities often results in disappointment and a loss of trust. The champion, who acts as a central body, is in a good position to monitor firms inside and outside of collaboration and to track their performance and behavior. The champion can then act to referee potential partners and vouch for their ability to perform.

An important issue with collaborator's involvement is their reluctance to share too much information due to the confidential nature of their business. This is especially important in the early days of collaboration while trust is still building. In this case, the champion can act as a trusted information conduit to ensure that all sides receive information they need, while closely managing information which is sensitive or confidential.

A final area of trust, supported by the champion, is to ensure collaborating partners maintain a business focus and that all potential distracters, like politics and personal relationships (I like working with him, I don't like her), are minimized. In the end of the day it is about the bottomline. If businesses don't make a profit, then no one wins: "The overriding theme for enabling collaboration is an offer of profitable business for the involved firms. Member manufacturers are essentially only interested in collaboration as an impact on their bottom line" (Interview Participant).

\section{Need to provide mentorship}

While there is a general need for mentoring, and many of the networks we researched provided mentoring from a leadership and management perspective, with regard to eCollaboration there is a specific need to build skills in the area of technical proficiency, especially with the internet and other ICT tools. "As many of the network's benefits are technology focused, many of the business operators lacked the technical knowledge and motivation to take part" (Interview Participant). The firms engaged in collaboration often deliberately steered clear of technical aids due to fear or ignorance. There were also differing levels of risk tolerance between firms, which created frustration when firm A was willing to use internet- based collaborative tools and firm B was unwilling. Champions can add a great deal of value by assisting firms to embrace technical aids to eCollaboration by ensuring each is competent with the tools they will need to optimize their partnership.

\section{Project Management}

Project management focuses on the more rigid elements of the collaboration, which are less easily manipulated by individuals. For example one of the champions involved in this study facilitated collaboration by establishing rules for exchange and by maintaining a delicate balance of approach to maintain collaborative activity without intervention. As there is little flexibility in these more structured elements of the individual businesses (i.e. rules of behaviour; project goals; team values; assurances of equity) they can create barriers between firms who would otherwise make good collaborative partners. A concern expressed by interview participants is the potential for inequity among the partner businesses in terms of control, shared values, and brand value. The role of the champion is to ensure the smooth process of inter-firm collaboration by managing these hard issues. There are three major needs that a champion must satisfy. First, there is a need 
to ensure that a system of democracy is built into each of the collaborations. Second, the champion needs to ensure there is an alignment of values and culture between collaborating companies. Finally, the champion must satisfy all of these hard and soft needs, while maintaining limited intervention. These needs are illustrated in Figure 5, and discussed in greater detail below.

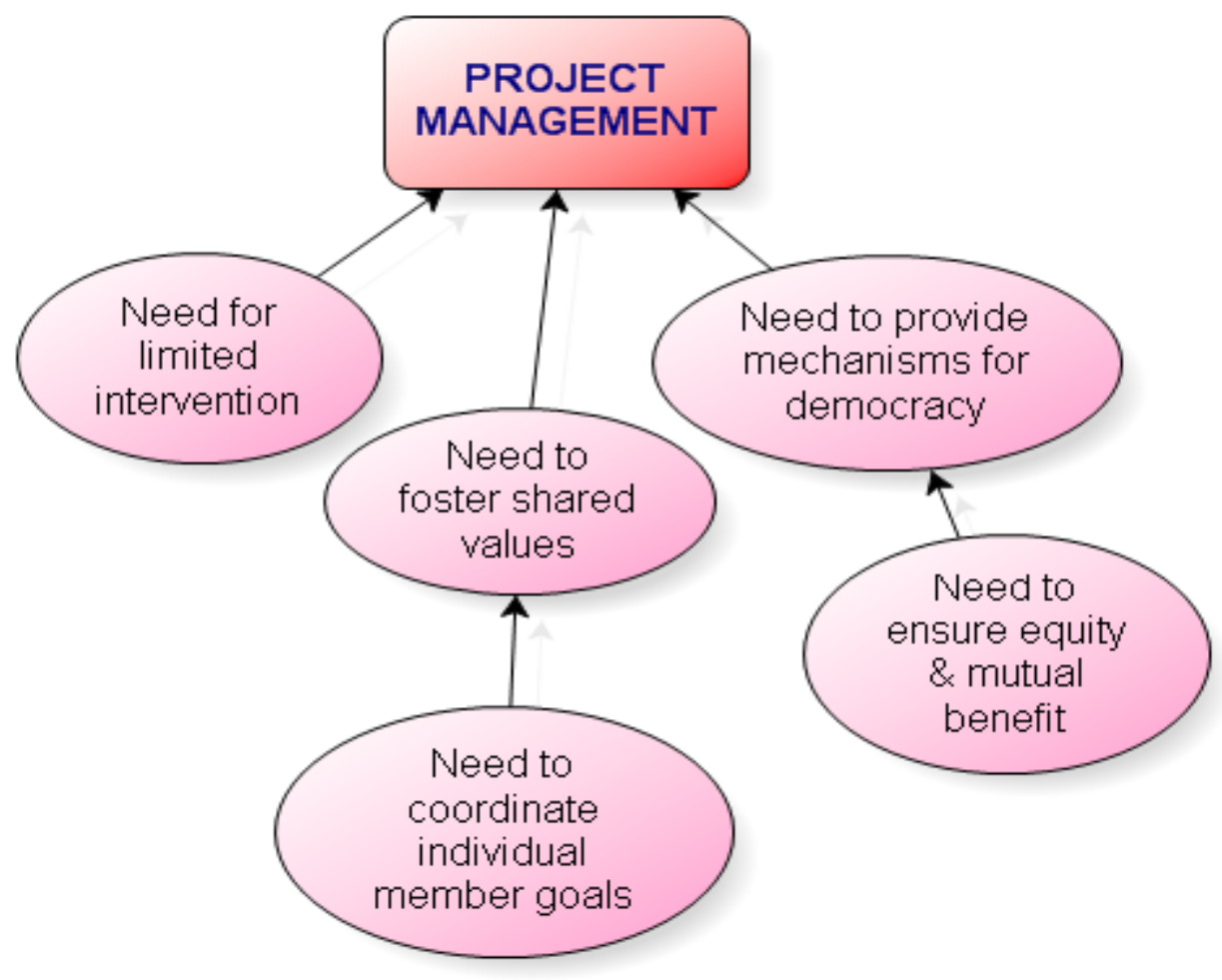

Figure 5. The Role of an eCollaboration Champion as a Project Manager

\section{Need to provide mechanisms for democracy}

The need for democratic structures is closely coupled to the need for assurances of equity and mutual benefit. In both of these there is a need for collaborators to be able to have equal say, equal control, and to have equal shares in costs and benefits. In some cases larger firms have taken advantage of smaller firms. This power inequity can lead to bitterness and a lack of trust, and sometimes leads to a failure of the collaboration. A champion can act to institute democratic mechanisms to ensure sufficient equities exist and are managed for the best interests of the group, the project, and the client. As a participant from a focus group explains, equity is essential for business success: "mutual benefits are essential for successful collaboration. If overtime, one party consistently benefits more than another, the collaboration is not sustainable." Further, even if benefits are reaped by all participants, there must still be an equal level of benefit in comparison to other participants that is maintained to ensure the sustainability of the collaboration.

\section{Need to foster shared values}

Firms enter into collaborative relationship for one ultimate reason - to increase profits, if not immediately, at least in the long-run. However, in attaining this outcome, firms collaborate to meet different needs. For example, firm A may collaborate with firm B to acquire knowledge and experience, or to access a new market, or to secure supply chains they didn't previously have. These reasons and needs are all legitimate and, providing they are explicit, should not create impedi- 
ments to a good business relationship. However, values and culture are a largely invisible force driving a firm's actions and behavior. The ability of values and culture to undermine what appears to be a solid partnership is uncanny. It is therefore important that firms become aware of each others values and, where possible, align them so that dissonance is reduced. For example, firm A may hold customer service high in its list of values, firm B, instead, may value cost efficiency. It is possible that these two values may be incompatible. So during the collaboration firm A will consume resources maintaining high levels of customer service and firm B will see this as a waste of money. This study came across this conflict when one partner of the collaboration wanted to expand the business into areas where they already had a high level of competence, while the other partner thought there were more opportunities for the venture if they took on new business in unexploited industries. This incompatibility in business direction ultimately led to a downfall of the relationship.

To be successful in collaboration, consensus on the goals and objectives of the group as a whole is imperative. A champion is able to see these goals independently and impartially and is able to mediate solutions and assist firms in adapting to a common culture and value system.

\section{Need for limited intervention}

While a champion has a great deal of scope to add value and create stability with new collaborations, the champion has to be careful to let businesses make their own decisions and focus on their own outcomes. Too high an involvement by the champion can be taken as meddling, which can lead to mistrust and can disrupt the whole process of championing the relationship. Participants from one focus group suggested: "One key success factor for [our champion] is the focus on providing the right amount of support for networking without getting involved with individual projects." In another focus group it was emphasized that "members must have complete control in how collaborative partnerships play out within the network. Objectives and organization for a business network cannot be pushed by any individual or organization that doesn't have the motivations of the [partnership] in mind." Therefore a champion needs to provide a framework and support for collaboration but cannot pressure a certain way of doing things.

\section{Marketing}

When businesses collaborate they usually do so for a particular business venture or goal. When this venture or goal is satisfied many collaborations continue and seek new work from other areas. A value-added service a champion can provide is to market the skills and services of this collaboration to other areas, both internally to network members and externally through a webportal. However, in contemplation of marketing, a conflict cycle emerges. A major driver of network success is the ability of a champion to provide value-added services like marketing; however, in order to do so, membership must be sufficiently large. A conflict occurs when membership costs are introduced. That is, the larger the membership, the larger the network, and the better the internal and external marketing; however, a large membership means increased costs, which means a charge must be placed on membership, which in turn has potential to reduce membership and increase the need for the champion to provide value-added services. This conflict means that a network will reach a balance between service and cost, and the size of any group will have consequent limits, that is, it is impossible for a network to maintain exponential growth.

Another dilemma of marketing is whether to focus on network strengths - that is the combined skills and experience of all members and, through the web-portal, act as a one-stop-shop where the champion will delegate work as it comes in - or whether to focus on business strengths - that is to advertise each individual member or partnership according to their individual skills and experiences. The first option provides the network more flexibility; collaborations can be assembled 
according to project needs, regardless of size of complexity. However, this requires a high level of input and management by the champion, who may later be accused of meddling or favoritism. The second option, is a far less hands-on approach, but means that work may be passed up if existing collaborations are not able to take on the new project.

Figure 6 illustrates the complexities involved in the role of marketing.

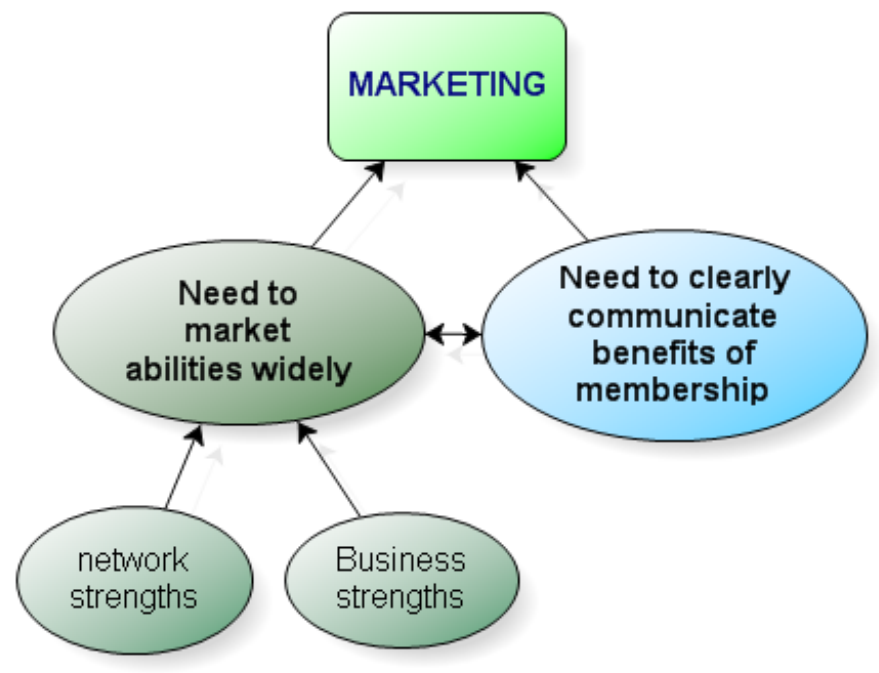

Figure 6. The Role of an eCollaboration Champion as a Marketer

\section{Feedback}

This final need - the need for feedback - enables the champion to manage information that comes from sources both internal to the network and external, from clients and other groups. As information is mainly collected through the web-portal, this function provides the collaborating partnership access to feedback which may otherwise be unavailable.

The integrated model of the eCollaboration Champion is exhibited in Figure 7. 


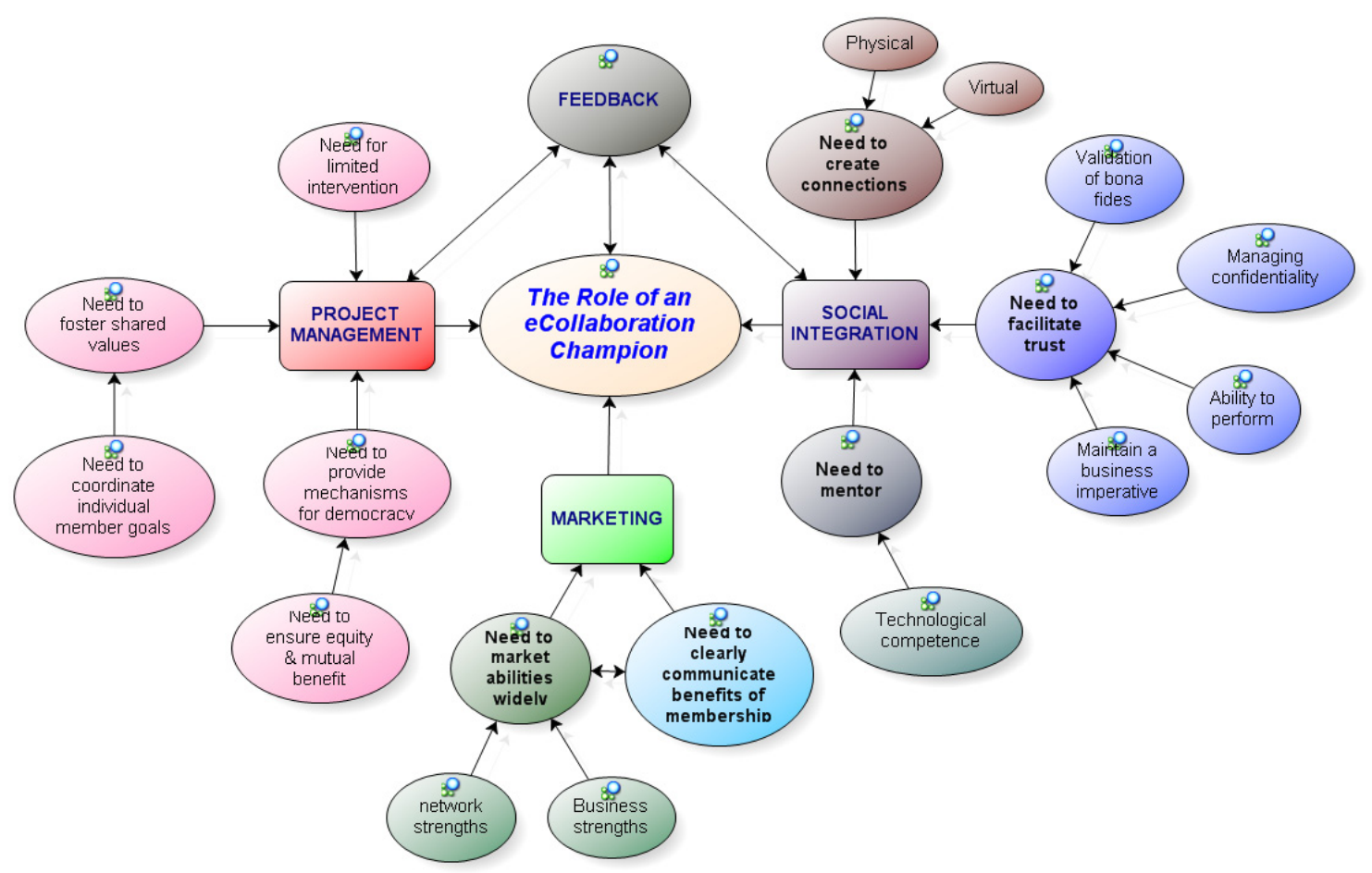

Figure 7. The integrated model of the Role of an eCollaboration Champion

\section{Discussion and Conclusion}

There are clear advantages to eCollaboration. However, in order to ensure success it is important that each eCollaboration is well supported. We contend that the best support for eCollaboration is for each network of firms to appoint an eCollaboration champion. The primary role of this position is to encourage and facilitate the collaboration of firms by fulfilling a range of needs. These needs are best described as soft needs, hard needs, marketing needs, and feedback. The important soft needs are for the champion to encourage social connection by creating face-to-face meeting opportunities and through an integrated web-portal. The champion must also manage and maintain trust, as well as train and mentor collaborators in ICT tools that support eCollaboration. With regard to hard needs the champion must ensure that a fair, equitable, and democratic system exists which provides equal opportunity for all participants; at the same time the champion needs to ensure that individual goals, objectives and cultures match as well as they can. Given the above however, the champion also needs to maintain a hands-off and non-interventionist approach to project management.

The provision of marketing by the champion is required to maximize collaboration potential and also to maximize value-added, both of which, in turn, justify service charges and ensure, to some extent, membership growth. The final element in this formula for eCollaboration success is the ability of the champion to provide collaborators with feedback. This information, usually acquired through the web-portal, helps to guide collaborators and to shape their success.

This case provides an expose on Australian SMEs, based on research in Southern Sydney. It may be of value to extend this research into other areas to test the validity of the model. 


\section{References}

Bryant, A. (2002). Re-grounding grounded theory. JITTA: Journal of Information Technology Theory and Application, 4(1) 25.

Burgess, L., \& Sargent, J. (2007). Enhancing user acceptance of mandated mobile health information systems: The ePOC (electronic Point-Of-Care Project) experience. Studies in Health Technology and Informatics, 129(2), 1088.

Cheng, E. W. L., Love, P. E. D., Standing, C. \& Gharavi, H. (2006). Intention to e-collaborate: Propagation of research propositions. Industrial Management and Data Systems, 106(1), 139-152.

Ginige, A. (2006). From eTransformation to eCollaboration: Issues and solutions. Keynote at 2nd International Conference on Information Management and Business, Sydney, Australia.

Glaser, B. G. (1978). Theoretical sensitivity: Advances in the methodology of grounded theory. Mill Valley, CA: Sociology Press.

Glaser, B. G. (1992). Basics of grounded theory analysis. Mill Valley, CA: Sociology Press.

Glaser, B. G. (1998). Doing grounded theory. Issues and discussions. Mill Valley, CA: Sociology Press.

Glaser, B. G. (2001). The grounded theory perspective: Conceptualization contrasted with description. Mill Valley, CA: Sociology Press.

Hanson, B. (2008). Wither qualitative/quantitative? Grounds for methodological convergence. Quality \& Quantity, 42, 97-111.

Jones, M. (2005). 'Lights... action... grounded theory': Developing an understanding for the management of film production. Rhyzome, 1(1), 143-153.

Jones, M., \& Burgess, L. A. (2009a). A tale of two case studies: A comparative analysis of eCollaboration among SMEs in Australia. APROS 13, 2009: Times, they are a changing: Understanding organizations in complex, emergent and uncertain environments, Monterrey, Mexico, Asia-Pacific Researchers in Organization Studies.

Jones, M., \& Burgess, L. A. (2009b). The mechanics of eCollaboration: Why it works - an empirical assessment of Australian SMEs. Social Innovation Network Conference, University of Wollongong.

Krueger, R. A. (1998). Analyzing and reporting focus group results. Thousand Oaks, CA: Sage.

Lawson, R., Hol, A., \& Hall. T. (2007). Challenges of eCollaboration among SMEs. 20th Bled eConference, eMergence: Merging and Emerging Technologies, Process and Institutions, Bled, Slovenia.

Ma, C. (2009). E-collaboration: A universal key to solve fierce competition in tourism industry? International Business Research, 1(4), 65-71.

Martin, P. Y., \& Turner, B. A. (1986). Grounded theory and organizational research. The Journal of Applied Behavioral Science, 22(2), 141-157.

Mayrhofer, D., \& Back, A. (2003). Workplace E-Collaboration theoretical foundations and practical implications (pp. 1-39). Institute of Information Management, University of St. Gallen.

Meixner, O., \& Haas, R. (2008). New product development of a yoghurt dessert via E-collaboration. 110th EAAE Seminar 'System Dynamics and Innovation in Food Networks', Innsbruck-Igls, Austria, European Association of Agricultural Economists, February 18-22.

Morgan, D. L. (1997). Focus groups as qualitative research. Thousand Oaks, California: Sage Publications.

Onwuegbuzie, A. J., \& Leech, N. L. (2007). Validity and qualitative research: An oxymoron? Quality \& Quantity, 41, 233-249.

Patton, M. Q. (1990). Qualitative evaluation and research methods. Newbury Park, CA: Sage Publications. 
Richards, T. (2002). An intellectual history of NUD*IST and NVivo. International Journal of Social Research Methodology, 5(3), 199-214.

Rowan, M., \& Huston. P. (1997). Qualitative research articles: information for authors and peer reviewers. Canadian Medical Association Journal, 157(10), 1442-1446.

Stern, A. J., \& Hicks, T. (2000). The process of business/environmental collaborations: Partnering for sustainability. Westport, USA, Quorum Books.

\section{Biographies}

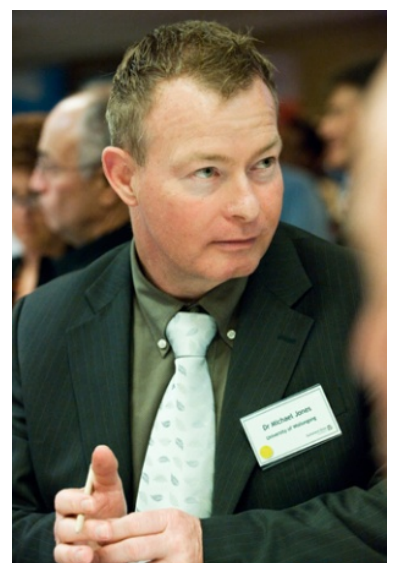

Michael Jones is a lecturer in Organizational Behavior in Australia's University of Wollongong. His recent writings focus on eCollaboration, especially with regard to small to medium enterprises. This has led to a number of competitive grants for research into this area. Early writings dealt with two principle areas; studies of qualitative methods, particularly in the field of grounded theory and computerized techniques for qualitative data analysis; and, organizational behavior, concentrating in areas of motivation and commitment. Michael received his $\mathrm{PhD}$ in organizational behavior from the University of Wollongong.

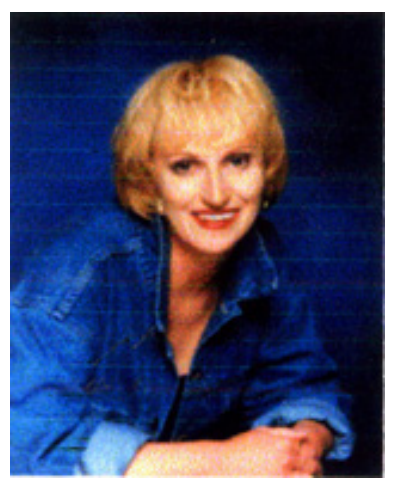

Dr Lois Burgess is a faculty member in the School of Management and Marketing in the Faculty of Commerce at the University of Wollongong, Australia. Lois worked for 20 years in industry in a range of middle and senior management positions before taking up her academic position at the University. Lois has extensive experience of teaching and development of courses in IT, Marketing and Public Relations. At present she teaches Public Relations and Marketing Communications. She received her Bachelor of Information Technology (Honours) and her $\mathrm{PhD}$ in Information Technology and Marketing from the University of Wollongong, Australia. Her current research interests centre on the adoption and use of electronic technology by Australian SMEs. Lois has researched extensively in this domain across a range of application areas including: eHealth, eCommerce, eBusiness, eTourism and more recently, eCollaboration. Lois has chaired.co-chaired multiple sessions/tracks in recognised National and International conferences. She is serving as Associate Editor of the International Journal of Technology and Small and Medium Enterprises and is serving as a member of the editorial review board of several refereed journals. 